\title{
Analytical predictions of moment curvature relationship of steel beam columns under fire attack
}

\author{
Haitham Al-Thairy* \\ Civil Engineering Department, College of Engineering, University of Al-Qadisiyah, Diwaniyah, Iraq
}

\begin{abstract}
Fire attack is one of the worst scenarios that may cause catastrophic consequences of steel buildings such as progressive collapse and failure. Current design codes and standards have addressed fire as one of the extreme loading conditions to be accounted for in the design of buildings. However, most of the approaches and procedures suggested by these codes and standards still lack accuracy and rationality. The purpose of this paper is to develop an analytical approach to predict the elastic-plastic moment-curvature relationship of steel beam columns section under elevated temperature. The analytical method was derived based on dividing the steel section to layers and integrating the resistance moment equation of each layer in terms of the section curvature taking into account the effect of elevated temperature on the material properties of the steel by using EC 3 reduction factors of the yield stress and modulus of elasticity. The suggested method has been validated against numerical simulation results. Validation results have shown the reliability of the suggested method to predict the resistance moment curvature relationship of steel beam-column members at different elevated temperatures and under different values of the axial compressive force. The suggested methods may be used to develop more accurate design approaches for steel beam columns under fire condition.
\end{abstract}

\section{Introduction}

Fire attack is one of the most dangerous incidents that may cause catastrophic consequences to steel buildings leading to progressive collapse and failure. Whilst current design codes and standards have addressed the fire load as one of the extreme loading conditions to account for in the design of steel buildings, most of the approaches and procedures suggested by these codes and standards still lack accuracy and rationality.

Section 3 of Part 1-2 in European Standards, EC1 [1] provides general rules to determine the thermal loads induced by fire to be used for assessment of steel members under fire attack such as determining of temperature - time curves for different fire exposures using heat transfer analysis. In addition, EC1 suggests procedures to determine the mechanical action of the fire based on prescriptive requirements. On the other hand, Part 1-2 of European standards, EC3 [2] have set out design procedures to predict structural resistance against fire. The code suggests that simplified analytical methods can be used for the design of isolated steel members exposed to fire assuming a uniform temperature in the cross-section taking into account the mechanical properties of steel at elevated temperatures. Temperature-dependent material properties for the structural steel have been suggested by the code including modulus of elasticity, effective yield stress and proportional limit along with thermal expansion, thermal conductivity and specific heat [2]. These values

can be used in analytical and numerical analyses of steel structures under elevated temperature. However, if non uniform temperature distribution is encountered, different temperature-dependent material properties must be proposed.

For example, Part 1-1 of EC3 [2] has suggested the following simple alternative method to calculate the reduced plastic bending moment capacity of steel sections at elevated temperature:

$$
M_{p f i}=\frac{k_{y, T} M_{p}}{\kappa_{1} \times \kappa_{2}}
$$

Where $M_{p}$ the plastic moment capacity of the steel is section at normal temperature; $k_{y, T}$ is the reduction factor for the yield strength of steel due to elevated temperature [2]. $\kappa_{1}$ is a factor used to account for non-uniform temperature distribution in the cross-section; and $\kappa_{2}$ is a factor used to calculate the support negative bending

Corresponding author: haitham.althairy@qu.edu.iq 
moment capacity when there is non-uniform temperature distribution along the beam [2]. From the equation above, it can be noticed that the effect of the axial compressive load is neglected which may result in overestimated values of the column plastic moment capacity.

The British Standards (BS5950) part 8 [3] has also suggested a bending moment capacity method as an alternative and accurate method for the design of steel structures exposed to non-uniform and uniform fire induced temperature. In this method, the plastic moment capacity of the steel section is calculated according to the reduced strengths of steel at each layer over the steel cross section. However, no guidance was given on how to consider the effect of the compressive axial force on the moment capacity of the section. Moreover, it has been shown by Wang [4] that BS5950 part 8 method would provide over estimated prediction of the section strength as compared to cases where the steel members fail during the elastic or the elastic-plastic phase of their response. However, for steel members subjected to axial load and bending moment BS5950 part 8 has suggested to use the limiting temperature method at which beam column load ratio can be obtained from the interaction equation of the column under combined axial load and bending moment at ambient temperature [3].

A considerable amount of experimental, numerical and analytical research studies have been published during the last decade on how to quantify the effect of elevated temperature on the behaviour and failure of steel members under fire. From these research studies, Dharma and Tan [5, 6] have conducted experimental and numerical studies to investigate the effect of elevated temperature on the rotational resistance of a stocky steel beam under a steady state fire condition. It has been found that fire has considerably reduced the rotational moment resistance of the steel beam section. It has also been shown that the moment-rotation and load-deflection responses of the elevated steel beams have followed same trends of the stress-strain behaviour of the steel under fire suggested by EC3 part 1-2 [2], which is characterized by a reduced yield strength and disappearance of the strain hardening behaviour. It has been concluded [5] that thermal reduction factors of yield stress and modulus of elasticity suggested by EC3 part 1-2 predominate the effect of temperature on rotational capacity whereas, increasing the flange, web and LTB slenderness ratios reduces the rotational capacity. Dharma and Tan [6] have also suggested a bilinear analytical model of the moment-rotation relationship of a compacted steel beams at elevated temperatures. The suggested model was based on numerical integration of moment-curvature linear relationship across the steel section. However, the effect of the axial compression of the moment- rotation relationship has not been considered in the suggested mode
Yin and Wang [7, 8] presented analytical model to investigate the effect of catenary action on behaviour of elastic perfectly plastic steel beams under uniform [7] and no uniform [8] elevated temperatures. The suggested methods use the equilibrium equation of the isolated beams and assume a polynomial deflection shape of the beams under lateral load corresponding to the beam loading and boundary conditions. For beams under non- uniform elevated temperatures, thermal bowing deflection has been accounted for to calculate the total deflection of the beam. The elastic moment resistance was determined using the elastic bending theory taking into consideration the reduction in modulus of elasticity and yield stress due to elevated temperature by using EC3 part 1-2 reduction factors [2]. The plastic moment resistance was calculated using the equilibrium of the forces exerted on the cross section when the steel material reached its yield limit taking into consideration the effect of axial tension force and the reduction in modulus of elasticity and yield stress due to elevated temperature. However, the effect of the axial compression force has also not been accounted for.

Choe et al. [9] have conducted experimental tests to investigate the moment-curvature response of hot rolled steel beam columns under a localized uniform temperature induced by fire. Experimental results have shown that the moment-curvature relationship was affected by the value of the elevated temperature. It has also been shown that the nonlinear behaviour of the moment-curvature relationship gets initiated earlier when the applied temperature is increased. These experimental test results can also be used to set out assumptions and to validate suggested analytical or numerical models to predict the moment-curvature response of steel beam columns under fire attack.

Walz et al. [10] has suggested a closed-form analytical model to determine the moment-curvature- relationship of steel beam columns subjected to uniform elevated temperatures under axial compression load. The suggested model assumes an elastic-perfectly plastic response of the steel material and uses steel material properties as described in Sec. 1-2 of EC3 [2]. MATLAB software was implemented to evaluate the section response using Newton-Raphson iterative procedure. However, inelastic behaviour was not included in the suggested model along with the unloading effects.

The ultimate aim of the current study is to derive an analytical method to predict the moment-curvature relationship of the steel beam column under uniform elevated temperature and different axial load levels. The suggested method was derived by dividing the steel section into numbers of fibres or layers and calculating the moment resistance of each layer taking into account the effect of elevated temperature on the material properties of the steel using EC3 reduction factors. The suggested method is validated against numerical simulation results. 


\section{Methodology}

The steel beam -column section shown in Fig. 1 is under combined bending moment and axial compressive load and subjected to elevated temperature. For the elastic-plastic phase of the beam-column deformations, strains at top and bottom layers of the steel section are assumed to exceed the proportional limit of the steel whereas strains at other layers are assumed within elastic range. The depth of yielding over the cross section in compression and tension zones measured from the top and bottom surfaces of the cross section are referred to hereafter, as $\mathrm{yc}(\mathrm{w})$ and $\mathrm{yt}(\mathrm{w})$ respectively. The strains at the top layer $\left({ }^{\varepsilon_{c, T o p}}\right)$ and at the bottom layer ( $\varepsilon_{t}$, Bottom $)$ of the elastic part of the cross section, corresponding to each value of transverse displacement $(\mathrm{w}+\Delta \mathrm{w})$, can be calculated as a function of the elastic curvature $(\varphi)$, total section depth (h), and depths of yielding at compression and tension zones (yc(w) and $\mathrm{yt}(\mathrm{w}))$, using the elastic bending theory as follows, see Fig. 1 .

$$
\begin{gathered}
\varepsilon_{c, t o p(w+\Delta w)}=\varepsilon_{\text {axial }}+\varphi \times\left(h-y_{c(w)}-y_{t(w)}\right) / 2 \leq \varepsilon_{f} \\
\varepsilon_{t, \text { bot. }(w+\Delta w)}=\varepsilon_{\text {axial }}-\phi \times\left(h-y_{c(w)}-y_{t(w)}\right) / 2 \geq-\varepsilon_{f}
\end{gathered}
$$

Where (w) is the accumulative value of the transverse displacement at the previous analysis step; $\Delta \mathrm{w}$ is the incremental value of the transverse displacement at the current analysis step; ${ }^{\varepsilon_{f}}$ is the fracture strain of the steel material; ${ }^{\varepsilon_{a x i a l}}$ is the axial strain due to the axial compressive load calculated by:

$$
\varepsilon_{\text {axial }}=\frac{P}{E_{T} A}
$$

Where $\mathrm{P}$ is the applied axial compression force, $E_{T}$ is the elastic modulus of elasticity of the steel at elevated temperature calculated using EC3 part 1-2 method (see Fig. 2) [2]; and A is the beam - column cross sectional area.

The elastic curvature of the beam column $\phi$ is calculated for the elastic part of the elastic-plastic section using the elastic bending theory by the following equation:

$$
\phi=\frac{\partial^{2} w(x)}{\partial x^{2}}
$$

Eq.5 must be evaluated at the location where the elastic plastic moment resistance is to be determined

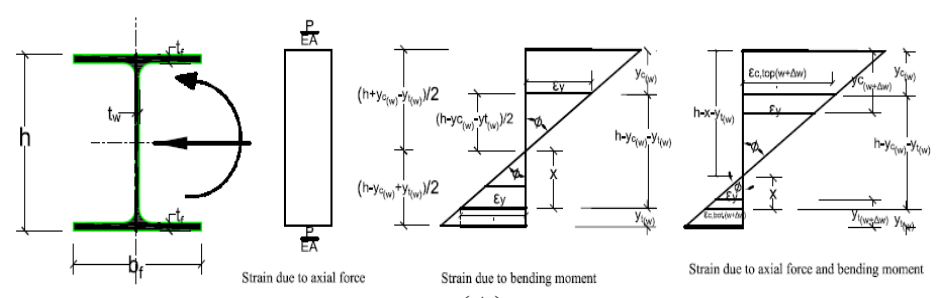

(A)
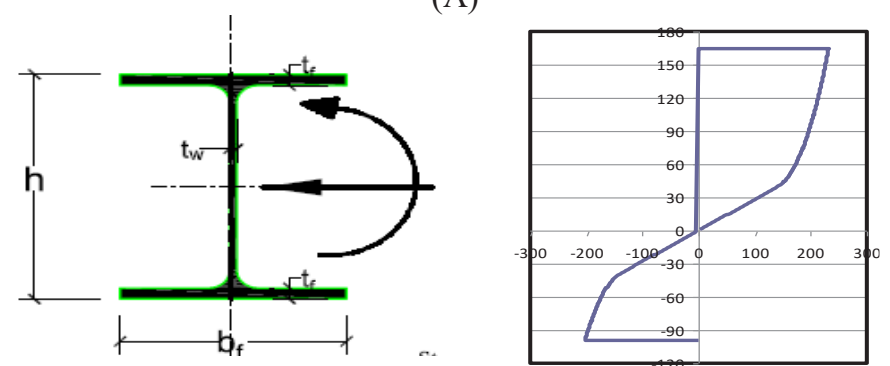

(B)

Fig. 1. Strain (A) and stress (B) distribution over a cross section of the steel column when bending is about the major axis.

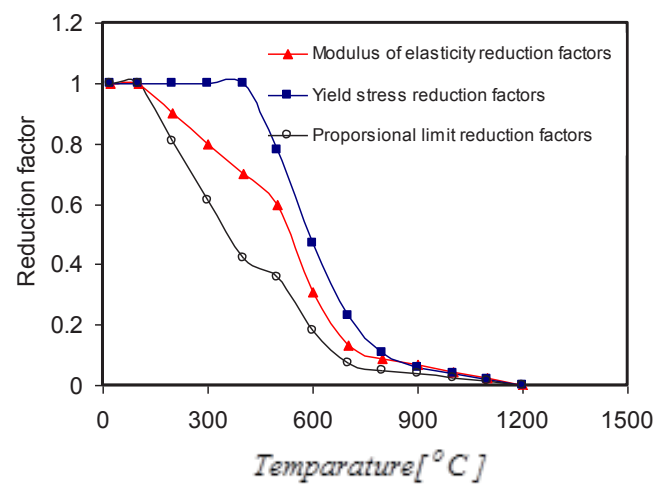

Fig. 2. EC3 reduction factors used in calculating the material properties of steel at elevated temperatures [2]

Yielding of the section is initiated when values of $\varepsilon_{c, t o p}(w+\Delta w)$ and $\varepsilon_{t}, b_{\text {bot. }(w+\Delta w)}$ calculated from Eqs.2 and 3, exceed the proportional limit strain of steel $\left({ }^{\varepsilon_{p}}\right)$ which can be calculated as:

$$
\varepsilon_{p}=\frac{f_{p_{T}}}{E_{T}}
$$

Where $f_{p T}$ is the proportional limit stress of the steel at elevated temperature determined using the method suggested by EC3 part 1:2 [2].

Values of $y \mathrm{c}_{(w+\Delta w)}, \quad y t_{(w+\Delta w)}$ are calculated accumulatively according to following incremental equations derived from trigonometric symmetry assuming a linear strain distribution over the elastic part of the section, see Fig. 1(A): 


$$
\begin{aligned}
& y_{c(w+\Delta w)}=y_{c(w)}+\left(h-y_{t(w)}-x_{(w)}\right) \times\left(1-\frac{\varepsilon_{p}}{\varepsilon_{c, t o p}}\right) \\
& y_{t_{(w+\Delta w)}}=y_{t(w)}+x_{(w)} \times\left(1-\frac{\varepsilon_{p}}{\varepsilon_{t}, \text { bott. }(w+\Delta w)}\right)
\end{aligned}
$$

Where $x_{(w)}$ is the distance from the first layer of the elastic part of tension zone to the neutral axis (N.A.) of the section as shown in Fig. 1 The value of $x_{(w)}$ is calculated from the previous analysis step using trigonometric symmetry as follows:

$$
x_{(w)}=\frac{h-y_{c(w)}-y_{t(w)}}{\left(1+\frac{\varepsilon_{c, t o p(w)}}{\left|\varepsilon_{t, b o t . w)}\right|}\right)}
$$

Eqs. 6 and 7 can be used to capture the gradual spread of yielding over cross section of the steel beam-column when the transverse displacement increases from $(w)$ to $(w+\Delta w)$.

Hence, the elastic-plastic bending resistance of a beamcolumn section under elevated temperature corresponding to each value transverse displacement $(w+\Delta w)$ can be calculated by integrating the moment resistance of all layers over the section depth as follows, see Fig. 1 (B):

$$
\begin{gathered}
M_{E l-P l}=\int_{-\kappa}^{\left(h-x-y_{t}-\kappa\right)} f c_{(T)} \times b_{I} \times d h \times\left[x+y_{t}+\left(\kappa+k_{l}\right)-\Delta h\right]+ \\
(x+t+\kappa) \\
\int_{\kappa} f t_{(T)} \times b_{l} \times d h \times\left[x+y_{t}-\left(\kappa-k_{2}\right)+\Delta h\right]-P \times \frac{h}{2}
\end{gathered}
$$

Where $f \mathcal{c}_{(T)}$ and $f t_{(T)}$ are stress at elevated temperature in compression and tension zones respectively. Values of $f_{\mathcal{C}_{(T)}}$ and $f t_{(T)}$ can be determined from the stress- strain curve of the steel at elevated temperature suggested by part 1:2 of EC3 [2[ as follows (see Fig. 3)

$$
\begin{array}{ll}
f_{\mathcal{C}_{(T)} \text { or } f t_{(T)}=\left(\varepsilon_{c} \text { or } \varepsilon_{t}\right) \times \mathrm{E}_{\mathrm{T}}} \quad \text { when }\left(\varepsilon_{c} \text { or } \varepsilon_{t}\right)<\varepsilon_{p} \\
f_{\mathcal{C}_{(T)} \text { or } f t_{(T)}=f p_{(T)}} & \text { when }\left(\varepsilon_{c} \text { or } \varepsilon_{t}\right)>\varepsilon_{p}<\varepsilon_{y} \\
f_{\mathcal{C}_{(T)} \text { or } f t_{(T)}=\mathrm{fy}_{(\mathrm{T})}} & \text { when }\left(\varepsilon_{c} \text { or } \varepsilon_{t}\right)>\varepsilon_{y}
\end{array}
$$

Where $\varepsilon_{y}$ is the yield strain of the steel at elevated temperature which assumed to be equal to 0,2 [2]; $f y_{(T)}$ is the effective yield stress. Values of $f p_{(T)}$ and $f y_{(T)}$ can be determined from the corresponding equations suggested by part 1:2 of EC3 [2] and they are not presented in this paper due to the lack of space. $\varepsilon_{c}, \varepsilon_{t}$ are values of strain at the corresponding layer of the compression and tension zones of the section respectively,. Values of $\varepsilon_{c}, \varepsilon_{t}$ can be calculated from the following equations assuming a linear strain distribution over the cross section depth as shown in Fig. 1:

$$
\begin{gathered}
\varepsilon_{c}=\varepsilon_{\text {axial }}+\phi \times k_{1} \leq \varepsilon_{f} \\
\varepsilon_{t}=\varepsilon_{\text {axial }}-\phi \times k_{2} \geq-\varepsilon_{f}
\end{gathered}
$$

Back to Eq.10, $\Delta \mathrm{h}$ is the incremental value of section depth which must be small enough to give accurate results $k_{1}$ and $k_{2}$ are distances from N.A. of the section assuming pure bending to the corresponding layer at which strain is to be determined at compression and tension zones respectively; $\kappa$ is the distance from the N.A. of the section at which the strain at the section under combined axial force and pure bending is equal to zero. However, $\boldsymbol{K}$ is measured from the N.A. of the section under pure bending which can be determined by setting the strain equations 14 or 15 equal to zero:

$$
0=\varepsilon_{\text {axial }}+\phi \times \kappa \Rightarrow \kappa=\left|\frac{-\varepsilon_{\text {axial }}}{\phi}\right|
$$

b1 and b2 are widths of the cross section layer in the compression and tension zones respectively and they are determined according to the location of the layer over the cross section as follows, see Fig. 1(A):

$$
\begin{aligned}
& \mathrm{b}_{1}=\mathrm{t}_{\mathrm{w}} \quad \text { when }(h-x-y t-\kappa)-t_{f} \geq k_{1} \geq-\kappa \\
& \mathrm{b}_{1}=\mathrm{b}_{\mathrm{f}} \text { when }(h-x-y t-\kappa) \geq k_{1} \geq(h-x-y t-\kappa)-t_{f} \\
& \mathrm{~b}_{2}=\mathrm{t}_{\mathrm{w}} \quad \text { when }\left(x+y_{t}+\kappa\right)-t_{f} \geq k_{2} \geq \kappa \\
& \left.\mathrm{b}_{2}=\mathrm{b}_{\mathrm{f}} \text { when }\left(x+y_{t}+\kappa\right) \geq k_{2} \geq\left(x+y_{t}+\kappa\right)-t_{f}\right)
\end{aligned}
$$

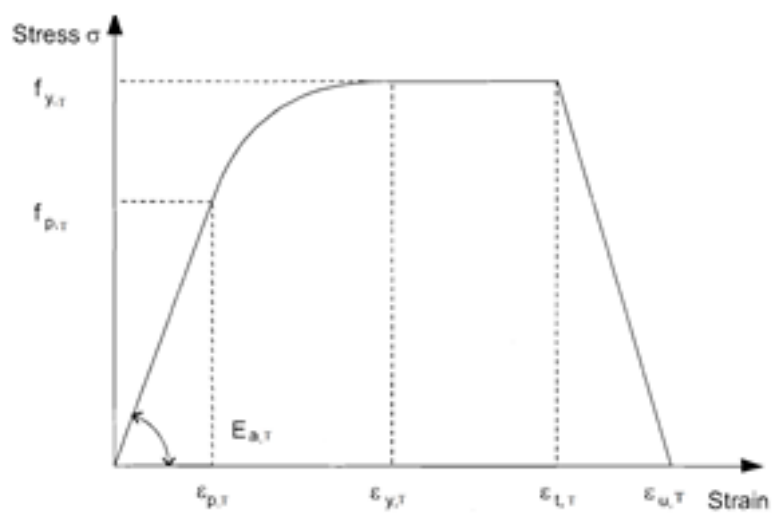

Fig. 3. Stress-strain relationship for structural steel at elevated temperatures [2].

\section{Validation}

The accuracy of the suggested analytical procedure is ascertained throughout comparison with numerical 
simulation results using the financial finite element software ABAQUS. A numerical simulation was carried out on a 1.6 meter length fixed base and free tip A992 W10×68 section steel beam column subjected to combined axial compression force and bending moment under elevated temperature [9]. The boundary and loading conditions of this case of the beam column was arranged to allow direct prediction of the moment-curvature response of steel beam columns under uniform elevated temperature, see Fig. 4. The beam columns were axially compressed to the intended axial load levels which are taken as a percentage of the column squash load ( $0.3 \mathrm{Py}$ and $0.5 \mathrm{Py})$ then subjected to uniform temperature over a $330 \mathrm{~mm}$ length at the fixed end where maximum moment and plastic hinge were expected to occur. After that, a lateral load was applied at the top end of the beam - columns and monotonically increased until the lateral displacement at this point was approximately equal to $150 \mathrm{~mm}$. Values of the yield and ultimate tensile stress were taken equal to $390 \mathrm{MPa}, 500 \mathrm{MPa}$ respectively [9]. Uniform elevated temperatures of $300^{\circ} \mathrm{C}$ and $500{ }^{\circ} \mathrm{C}$ were applied to the beam-column over the outer surfaces of the flanges and both surfaces of the web at the fixed end using a temperature rate (temperature -time curves) as shown in Fig. 5. Table 1 shows the geometry and loading condition of the simulated beam column members.

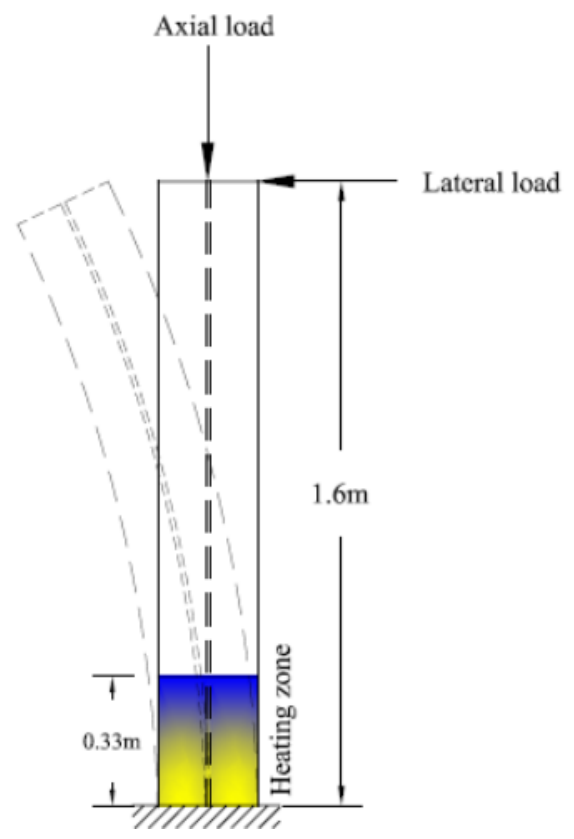

Fig. 4. Geometry and loading conditions of the steel beam-column example [9].

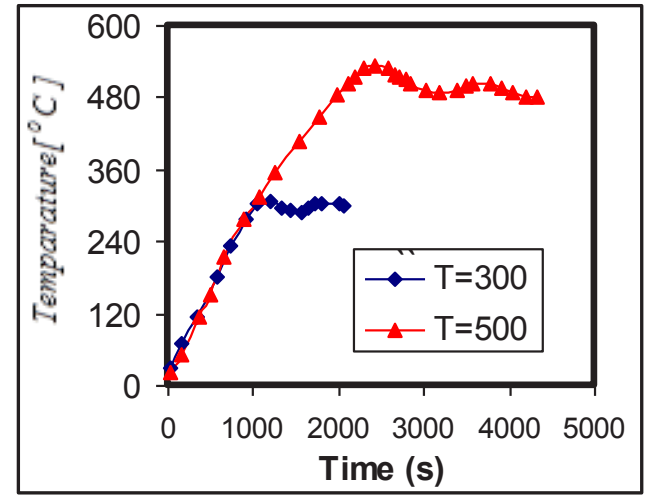

Fig. 5. Temperature-time curves used to apply the elevated temperatures [9]

Table 1. Geometry and loading properties of the beam-column specimens

\begin{tabular}{|c|c|c|c|c|c|c|}
\hline 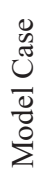 & 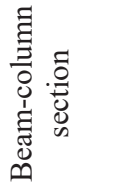 & 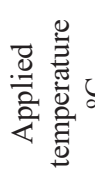 & 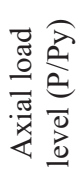 & 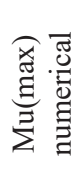 & 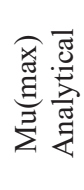 & 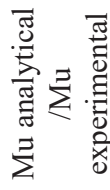 \\
\hline 1 & W10×68 & 20 & 0.3 & 499 & 435 & 0.87 \\
\hline 1 & W10×68 & 20 & 0.5 & 382 & 304 & 0.8 \\
\hline 2 & W10×68 & 300 & 0.3 & 522 & 432 & 0.83 \\
\hline 3 & W10×68 & 300 & 0.5 & 477 & 410 & 0.86 \\
\hline 4 & W10×68 & 500 & 0.3 & 383 & 326 & 0.85 \\
\hline 5 & W10×68 & 500 & 0.5 & 272 & 264 & 0.97 \\
\hline
\end{tabular}
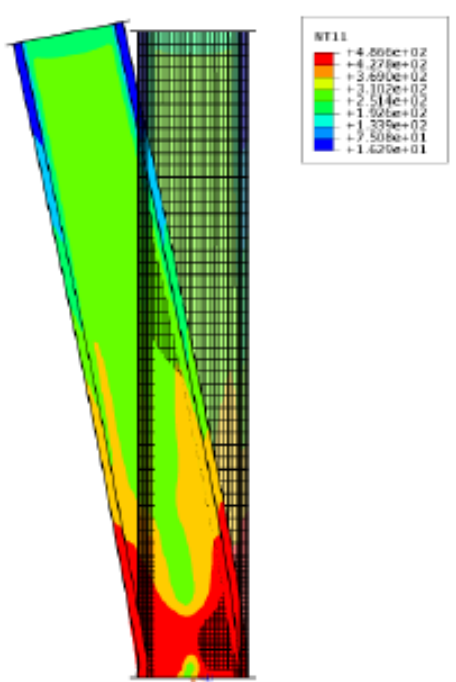

(A)

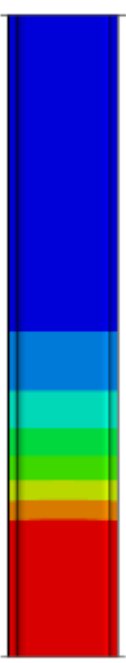

(B)
Fig. 6. A) Geometry of the steel beam-column model used in numerical simulations; B) temperature distribution over the steel column obtained from heat transfer analysis 
The sequential thermal mechanical analysis procedure available in ABAQUS/Standard was utilized in this study to simulate the behaviour of the steel beam-column members under elevated temperature. In this sequential procedure, a heat transfer analysis was firstly carried out to determine the temperature distribution over the length and over the crosssection of the beam-column member. In the heat transfer analysis, the 8-node linear heat transfer brick element (DC3D8) was used to model the beam-column member using a mesh size of $10 \mathrm{~mm}$ at the heated zone and mesh size of $30 \mathrm{~mm}$ at the rest of the beam-column as shown in Fig. . The elevated temperature was applied as a boundary condition in the heat transfer analysis step using a tabular temperature time amplitude available in ABAQUS/Standard as shown in Fig.4.

The heat transfer analysis was followed by a mechanical or structural analysis to determine the behaviour of the axially loaded beam-column under fire. In this analysis the 8-node linear brick with reduced integration and hourglass control (C3D8R) was employed to model the geometry of steel members using same mesh size used in the heat transfer analysis. The EC3 stress - strain curves shown in Fig. was used to model the material behaviour of steel under elevated temperatures. Furthermore, EC3 reduction factors of the yield stress, proportional limit, and modules of elasticity were used to account for the effect elevated temperate on the stress-strain response of the steel material as shown Fig. . The fixed end of the steel beam-column members were simulated by restraining all degrees of freedom at the column base.

During the mechanical or structural analysis, the axial compression load was firstly applied as a pressure load in a static analysis step followed by another static analysis step at which the temperature distribution over the steel beam column was restored from the heat transfer analysis procedure using the PREDEFINED FEILED option available in ABAQUS. Finally, a lateral concentrated static force was applied at the column free end during static analysis step until the column experienced large displacement. The moment-curvature relationship was obtained from the numerical load-displacement results at each simulation. The moment at the column base was obtained by multiplying the concentered lateral loads by the distance between the load and the plastic hinge location which is approximately equal to $1.5 \mathrm{~m}$. The elastic curvature at the plastic hinge location is obtained from the equation obtained from the elastic bending theory whereas; the elastic- plastic curvature is obtained from the numerical differentiation.

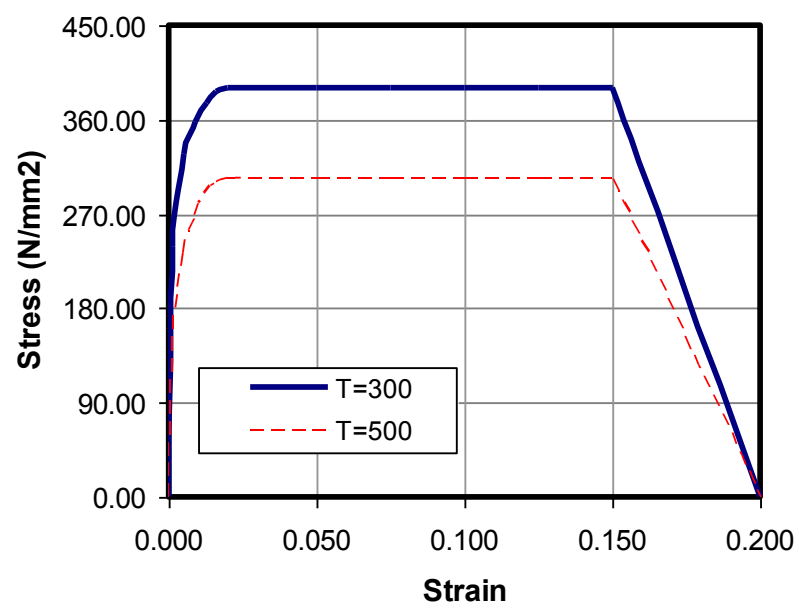

Fig. 7. Stress-strain relationship for structural steel at elevated temperatures used in the numerical simulations.

On the other hand, the suggested analytical method has also been used to predict the moment-curvature relationship of the same problem. However, implementation of the procedure described in section II requires determining the elastic curvature equation of the beam - column according to the assumed elastic deformation shape, which must satisfy the loading and the ends support conditions. For a fixed base and free tip column, Timoshenko and Gere [11] have suggested the following equation of the elastic deformation shape:

$$
w_{(x)}=W\left(1-\cos \left(\frac{\pi x}{2 L}\right)\right.
$$

Where $\mathrm{W}$ is the amplitude of the elastic deformation shape; $\mathrm{L}$ is the length of the beam-column member and $\mathrm{x}$ is the distance along the beam -column length at which elastic displacement is to be calculated. Hence, elastic curvature equation can be determined from Eqs. 5 and 21 as:

$$
\phi=\frac{\partial^{2} \mathrm{w}(\mathrm{x})}{\partial \mathrm{x}^{2}}=\mathrm{W}\left(\frac{\pi}{2 \mathrm{~L}}\right)^{2} \cos \left(\frac{\pi \mathrm{x}}{2 \mathrm{~L}}\right)
$$

And the curvature at the column's base, where the maximum moment would occur, can be determined by substituting $\mathrm{x}$ in Eq. 22 by null as follows:

$$
\phi=W\left(\frac{\pi}{2 L}\right)^{2}
$$

Fig. 8, Fig. 9 and Fig. 10 show the comparison between the numerical and analytical predictions of the moment curvature relationship of the steel beam-column under different axial load levels and subjected to two values of the elevated temperature. As can be seen from the figures, reasonable agreement was obtained between the two sets of results indicating reliability of the suggested method. It can also be noticed from Figs. 8 to 9 that with an increase in the axial load values, the agreement between the proposed 
analytical and numerical results increases accordingly. Moreover, Figs. 8 and 9 indicate that with an increase in the degree of the elevated temperature, more agreement can be obtained between analytically and numerically predicted results.

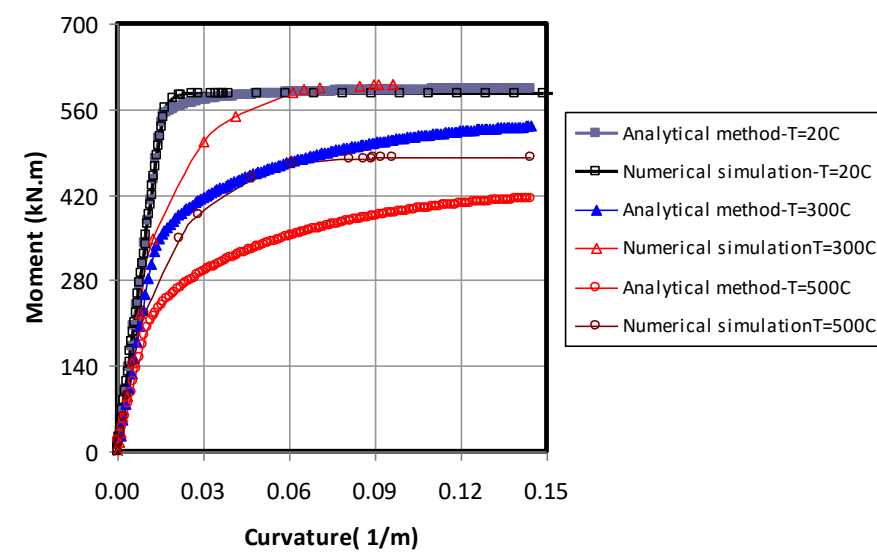

Fig. 8. Moment curvature relationships of the steel beam-column section W10 $\times 68$ subjected to different elevated temperatures with no axial compressive load

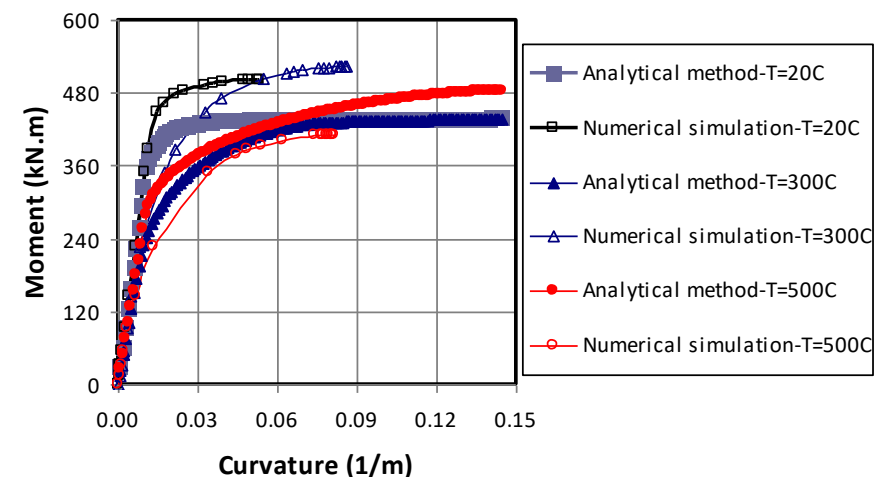

Fig. 9. Moment curvature relationships of the steel beam-column section $\mathrm{W} 10 \times 68$ subjected to different elevated temperatures under axial compressive load of $0.3 \mathrm{Py}$.

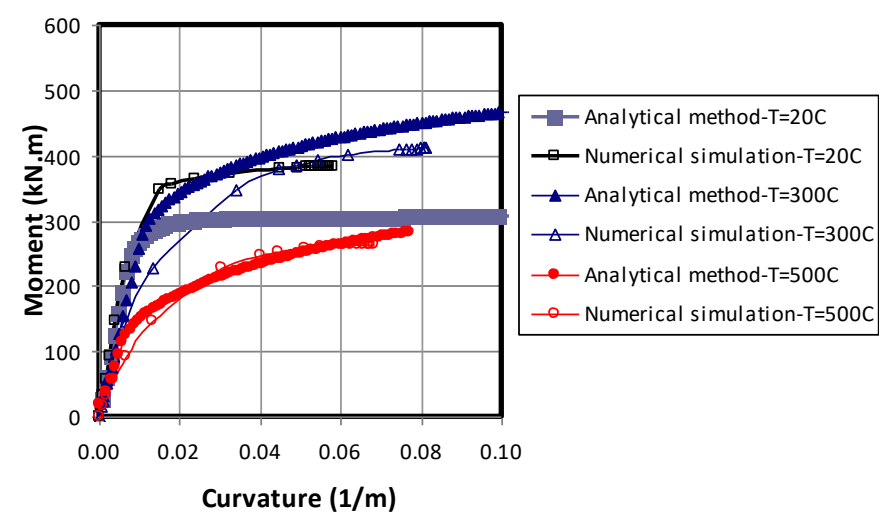

Fig. 10. Moment curvature relationships of the steel beam-column section $\mathrm{W} 10 \times 68$ subjected to different elevated temperatures under axial compressive load of $0.5 \mathrm{Py}$.

Units

\section{Parametric study}

A parametric study is carried out in this section using the suggested and validated analytical method to investigate the effect of elevated temperature on the moment-curvature response of steel beam-column section under a compression force equal to $50 \%$ of the section squash load (Py) and the results are shown in Fig. . As can be seen from this figure, a considerable reduction in the predicted moment of the section is obtained when the elevated temperature is increased. It can also be noticed from Fig. 11 that the linear elastic part of the moment-curvature relationship gets vanished with increasing elevated temperature. This behaviour is conforms to the disappearance of the strain hardening behaviour indicated experimentally in Dharma and Tan study [5] and Choe et al. [9] and the suggested analytical method could predict this behaviour reasonably.

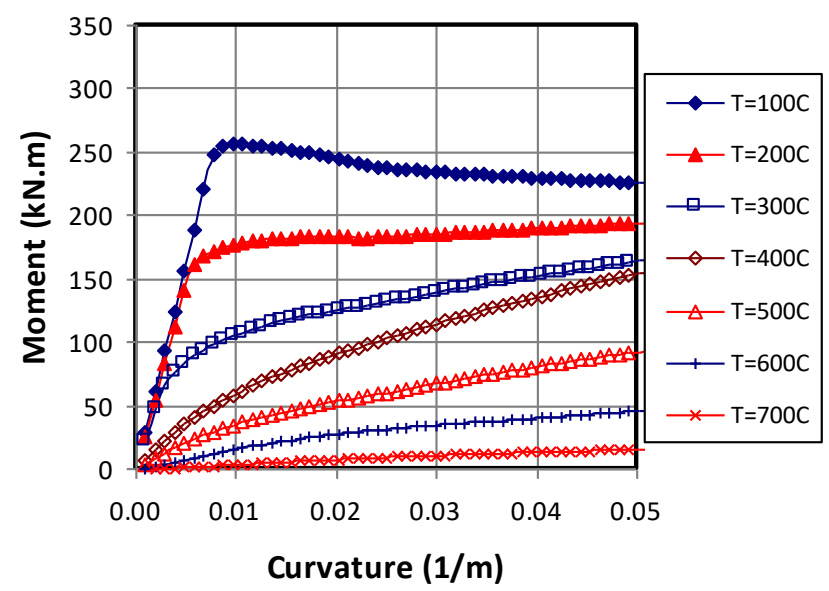

Fig. 11. Effect of elevated temperatures on the moment-curvature response of steel beam-column section.

Fig. illustrates the effect of elevated temperature on the stress distribution over the cross section of the steel beamcolumn subjected to same value of the axial compression force. It is clearly shown from Fig. 12 that with an increase in the elevated temperature, the depths of compression zone increased owing to the reduction in the stresses caused by the elevated temperatures [2]. When the compressive stress decreases, a more compression area is needed to achieve the equilibrium of forces acting on the section. 


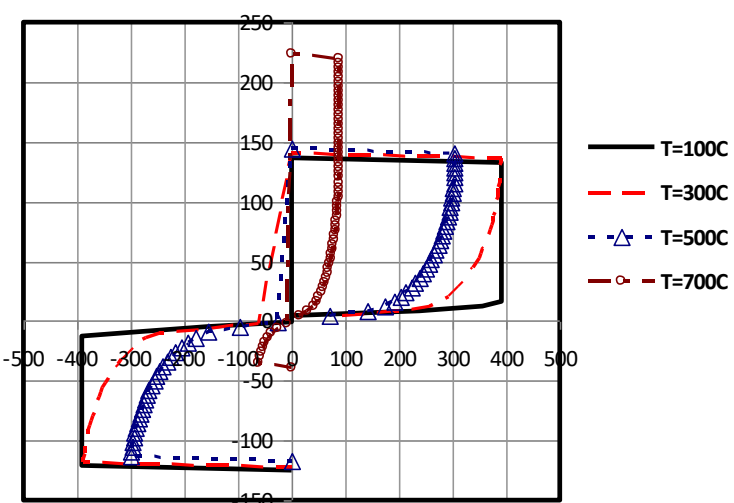

Fig. 12. Effect of elevated temperature on the stress distribution over the cross section of the steel beam column

\section{Conclusions}

This paper has presented a development of an analytical method for prediction of the elastic-plastic momentcurvature relationship of steel beam - columns section under elevated temperatures. The suggested analytical approach divides the steel section to numbers of layers and integrates the moment equation of the single layer over the entire section depth taking into account the degradation of the steel material properties due to the effect of elevated temperature using EC3 reduction factors. The suggested analytical method has been validated against numerical simulation results which have shown the reliability of the suggested method. The suggested methods may be used to develop more accurate design approaches for steel beam columns under fire condition.

A parametric study is carried out to investigate the effect of elevated temperature on the moment-curvature response of steel beam-column section showing that a considerable reduction in the predicted moment of the section occurred with reducing the linear elastic part of the moment-curvature relationship when the elevated temperature is increased. It has also been concluded that with an increase in the elevated temperature, the depths of compression zone also increases.

\section{References}

1. EC 1: Actions on structures - Part 1-2: general actions - Actions on structures exposed to fire. EN 1991-12:2002 (European Committee for Standardization, 2002).

2. EC 3: Design of steel structures - Part 1-2: General rules - Structural fire design. EN 1993-1-2:2005 (European Committee for Standardization; 2004).
3. BS5950: Part 8:1990: Code of Practice for Fire Resistant Design (The steel construction institute, 1993)

4. 2nd ed (Taylor and Francis e-Library, 2005)

5. R.B. Dharma, K.H. Tan, Eng. Str., 29, 2391-2402 (2007)

6. R.B. Dharma, K.H. Tan, Eng. Str., 29 , 2403-2418, (2007)

7. Y.Z. Yin, Y.C. Wang, Jour. of Const. Ste. Res., 61, 183-211(2005)

8. Y.Z. Yin, Y.C. Wang. Jour. of Con. Ste. Res., 61, 213$234(2005)$

9. L. Choe; A. H. Varma, A. Agarwal; and A, Surovek, Jour. of Str. Eng., 127, 954-966 (2001)

10. J. Walz1, A. Surovek, A. Agarwal, L. Choe, A.Varma, (Council Pittsburgh, Pennsylvania, 2011)

11. S. P Timoshenko, J. M. Gere "Theory of Elastic Stability" 2nd ed. (McGraw-Hill, NY, 1985) 